OPEN ACCESS

Edited by:

Fang Liu,

Guangzhou University of Chinese

Medicine, China

Reviewed by:

Hang Xing

Hunan University, China

Jinping Wang,

University of Jinan, China

${ }^{*}$ Correspondence:

Chao Teng

tengchao@szpt.edu.cn

Qianhao Min

minqianhao@nju.edu.cn

Specialty section:

This article was submitted to Nanoscience,

a section of the journal

Frontiers in Chemistry

Received: 16 June 2020

Accepted: 24 August 2020

Published: 23 October 2020

Citation:

Li K, Teng C and Min Q (2020) Advanced Nanovehicles-Enabled Delivery Systems of Epigallocatechin

Gallate for Cancer Therapy.

Front. Chem. 8:573297.

doi: 10.3389/fchem.2020.573297

\section{Advanced Nanovehicles-Enabled Delivery Systems of Epigallocatechin Gallate for Cancer Therapy}

\author{
Kai Li ${ }^{1,2}$, Chao Teng ${ }^{1 *}$ and Qianhao Min ${ }^{2 *}$ \\ ${ }^{1}$ Shenzhen Polytechnic, Institute of Marine Biomedicine, Shenzhen, China, ${ }^{2}$ State Key Laboratory of Analytical Chemistry for \\ Life Science, School of Chemistry and Chemical Engineering, Nanjing University, Nanjing, China
}

Epigallocatechin gallate (EGCG) is the most abundant polyphenolic constituent derived from green tea extract, which has demonstrated versatile bioactivities in combating cardiovascular diseases, neurodegenerative diseases, diabetes, and cancer. In light of its anticancer activity, increasing attention has been paid to developing potent strategies involving EGCG in cancer chemotherapy. However, the poor bioavailability and stability of EGCG limits its effectiveness and practicality in real biomedical applications. To overcome this drawback, nanotechnology-facilitated drug delivery systems have been introduced and intensively explored to enhance the bioavailability and therapeutic efficacy of EGCG in cancer treatments and interventions. This review briefly discusses the anticancer mechanisms of EGCG, and then summarizes recent advances in engineering nanovehicles for encapsulating and delivering EGCG toward cancer therapy. In addition, we also highlight successful integrations of EGCG delivery with other chemotherapies, gene therapies, and phototherapies in one nanostructured entity for a combination therapy of cancers. To conclude, the current challenges and future prospects of the nanovehicle-based transportation systems of EGCG for cancer therapy are also discussed.

Keywords: EGCG, cancer, nanovehicles, drug delivery systems, combination therapy

\section{INTRODUCTION}

Natural products hold great potential in the fields of biomedical research, drug development, and clinical application, as they can serve as medicinal sources for the treatment of cancer, bacterial and fungal infections, inflammation, and other diseases (Mignani et al., 2018). Particularly, the superior biocompatibility, broad spectrum of biological activity, and specifically targeted effects of these compounds make them potent cancer chemoprevention and chemotherapy agents with minimal side effects (Cragg et al., 2009; Spradlin et al., 2019). Moreover, these abundant and widely varied sources can reduce the cost of cancer treatment. Epigallocatechin gallate (EGCG) is known as the most biologically active catechin derived from green tea extracts. Benefiting from the eight free hydroxyl groups in its flavone-3-ol phenolic structure (Figure 1), EGCG demonstrates unique merits in free radical scavenging, accounting for its biological functions in biomedicine (antioxidation, anti-inflammatory, reduction of blood lipids, and sugar, etc.) (Cai et al., 2006; Chakrawarti et al., 2016). Since the recognition of its anticancer effects, EGCG has in recent years been intensively investigated as a star phytochemical for regulating or inhibiting the physiological changes during canceration (Singh et al., 2011; Granja et al., 2016; Gan et al., 2017). 


\section{e.g. self-polymer- -ization of EGCG on the surface of nanovehicels}

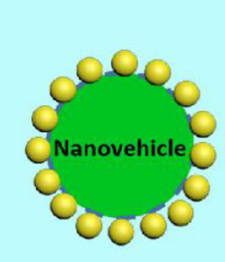

\section{(3)}

\section{e.g. peptides, aptermers

Targeting
delivery of
EGCG to
tumor tissues

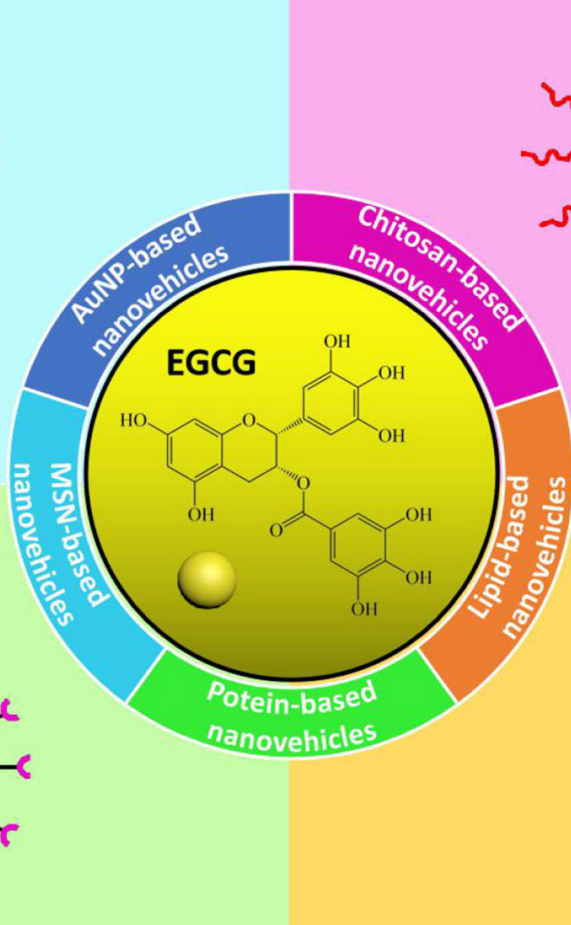

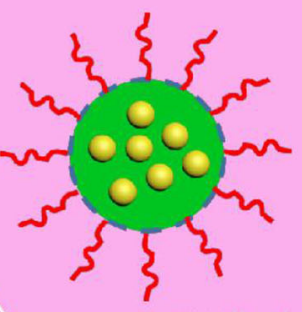

e.g. chitosan, folic acid, gallic acid, chlorogenic acid

Cotributing to cellular uptake and increasing stability of the nanovehicles; endowing controllable release of EGCG

(4)

e.g. chemotherapeutic drugs, therapeutic genes, photo-sensitizers

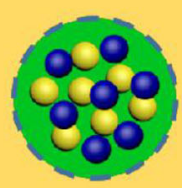

Realizing combination therapy of cancer

\section{Targeted molecular modification}

\section{Multi-modal therapeutics co-delivery}

FIGURE 1 | Summary of EGCG delivery systems: (1) grafting EGCG on the surface of the nanoparticles to enhance cellular uptake of as-obtained nanovehicles; (2) surface functionalization with specific molecules (chitosan, folic acid, gallic acid, and chlorogenic acid) to enhance stability, cellular uptake, and drug release properties of the nanovehicles; (3) targeted molecular modification by peptides or aptamers to target specific cancer cell receptors; (4) construction of multi-modal therapeutics co-delivery systems to realize EGCG-involved cancer combination therapy.

According to previous literature, the anticancer mechanism of EGCG involves many pathways. Specifically, the tumor suppressive behavior of EGCG through pro-oxidative effects is based on covalent binding of EGCG with antioxidants such as glutathione (GS), then producing a certain amount of reactive oxygen species (ROS) to activate the pro-oxidative signaling pathways (Shankar et al., 2012) and induce apoptosis of tumor cells (Li et al., 2010). EGCG can also target a variety of cancerrelated membrane receptors (Singh and Katiyar, 2013) or nucleus signaling receptors (Shankar et al., 2012) and down regulate or inhibit their abnormal expression, therefore inhibiting the proliferation and metastasis of tumor cells. Evidence also shows that EGCG modulates signaling cascades to induce programmed cell death through activating protein kinases (Zhu et al., 2017). Additionally, suppression of vascular endothelial growth factor (VEGF) (Wang J. et al., 2018), eliminations of cancer stem cell (CSC)-characteristics (Xia and $\mathrm{Xu}, 2015$ ), and down-regulation of telomerase (Sadava et al., 2007; Berletch et al., 2008) have been proposed to be involved in the curative mechanisms of EGCG.
In view of its anticancer activity, EGCG has been exploited as a potent chemotherapeutic agent for various cancers. However, the poor bioavailability and stability of EGCG restricts its clinical applications. As shown by Nakagawa and Miyazawa (1997) the maximum concentration of EGCG is calculated as $0.32 \%$ of ingested EGCG in human plasma through oral administration, which is too low to exhibit ideal efficacy. The methylation, glucuronidation, sulfation, and oxidative degradation of EGCG during its metabolic process further weakened its efficacy. Therefore, it is essential to develop novel drug delivery systems that enhance the stability and bioavailability of EGCG, thus ensuring the effective concentration and bioactivity in vivo (Yang et al., 2019). As the use of nanotechnologyfacilitated biomedicine in the past decades has flourished, encapsulating EGCG within nanovehicles has been adopted by many researchers (Granja et al., 2016; Ye and Augustin, 2018). The protection imparted by nanovehicles allowed the isolation of entrapped EGCG from the outer physiological conditions, thus avoiding the probable compositional and structural change 
TABLE 1 | Summary of gold-, mesoporous silica-, lipid-, chitosan-, and protein-based EGCG delivery systems.

\begin{tabular}{|c|c|c|c|c|c|c|c|}
\hline $\begin{array}{l}\text { EGCG nano- delivery } \\
\text { system }\end{array}$ & $\begin{array}{l}\text { Synthetic } \\
\text { method }\end{array}$ & $\begin{array}{l}\text { Particle size } \\
\text { (nm) }\end{array}$ & $\begin{array}{l}\text { Encapsulation } \\
\text { efficiency } \\
(\%)\end{array}$ & $\begin{array}{l}\text { Release of } \\
\text { EGCG }\end{array}$ & $\begin{array}{l}\text { Cell } \\
\text { lines/animal } \\
\text { models }\end{array}$ & Achievement & References \\
\hline \multicolumn{8}{|c|}{ Gold nanoparticles-based EGCG delivery systems } \\
\hline EGCG-AuNPs & $\begin{array}{l}\text { Reduction of } \\
\text { sodium tetrachloro } \\
\text { aurate by EGCG }\end{array}$ & $20-40$ & - & - & PC-3 cells & $\begin{array}{l}\text { EGCG-AuNPs internalize selectively } \\
\text { within PC3 cells providing threshold } \\
\text { concentrations required for } \\
\text { photoacoustic signals. }\end{array}$ & Viator et al., 2010 \\
\hline $\begin{array}{l}\text { EGCG-gold } \\
\text { nanoparticles (E-GNPs) }\end{array}$ & $\begin{array}{l}\text { Reduction of } \\
\mathrm{HAuCl}_{4} \cdot 3 \mathrm{H}_{2} \mathrm{O} \text { by } \\
\text { EGCG }\end{array}$ & 25 & $0.235(w / w)$ & $\begin{array}{c}42.9 \%\left(37^{\circ} \mathrm{C}\right. \\
48 \mathrm{~h})\end{array}$ & $\begin{array}{l}\text { A375SM, } \\
\text { MDA-MB- } \\
\text { 231, MIA } \\
\text { PaCa, and } \\
\text { PC-3 cells }\end{array}$ & $\begin{array}{l}\text { E-GNPs can effectively inhibit the } \\
\text { nuclear translocation and } \\
\text { transcriptional activity of nuclear } \\
\text { factor-kappaB (NF-kB) and induce } \\
\text { apoptosis in cancer cells. }\end{array}$ & $\begin{array}{l}\text { Chavva et al., } \\
2019\end{array}$ \\
\hline $\begin{array}{l}\text { EGCG-radioactive gold } \\
\left({ }^{198} \mathrm{AuNPs}\right) \\
\text { nanoparticles }\end{array}$ & $\begin{array}{l}\text { Reduction of } \\
\mathrm{H}^{198} \mathrm{AuCl}_{4} \cdot 3 \mathrm{H}_{2} \mathrm{O} \\
\text { by EGCG }\end{array}$ & $15-40$ & - & - & $\begin{array}{l}\text { PC-3 } \\
\text { xenograft } \\
\text { SCID mice }\end{array}$ & $\begin{array}{l}\text { The ability of EGCG to target laminin } \\
\text { receptor (67LR) leads to the } \\
\text { internalization of EGCG- }{ }^{198} \text { AuNPs } \\
\text { into prostate tumor cells, increasing } \\
\text { the radiotherapeutic effect of } \\
{ }^{198} \text { AuNPs in reducing tumor volumes. }\end{array}$ & Shukla et al., 2012 \\
\hline EGCG-pNG particles & $\begin{array}{l}\text { EGCG and pNG } \\
\text { were physically } \\
\text { mixed via } \\
\text { ultrasonication }\end{array}$ & 50 & 27 & $\begin{array}{l}36.2 \%\left(36^{\circ} \mathrm{C}\right. \\
\mathrm{pH} 1.2,0.5 \mathrm{~h})\end{array}$ & $\begin{array}{l}\text { MBT-2 tumor } \\
\text { cells and } \\
\text { female } \\
\mathrm{C} 3 \mathrm{H} / \mathrm{He} \text { mice }\end{array}$ & $\begin{array}{l}\text { EGCG-pNG mediated tumor } \\
\text { apoptosis was demonstrated to } \\
\text { involve activation of the caspase } \\
\text { cascade, via the Bcl-family proteins, } \\
\text { of the mitochondrial pathway. }\end{array}$ & Hsieh et al., 2012 \\
\hline $\begin{array}{l}\text { EGCG-physical } \\
\text { nanogold (pNG) } \\
\text { particles }\end{array}$ & $\begin{array}{l}\text { EGCG and pNG } \\
\text { were physically } \\
\text { mixed via } \\
\text { ultrasonication }\end{array}$ & $64.7-127.4$ & 29 & - & $\begin{array}{l}\text { murine } \\
\text { B16F10 } \\
\text { melanoma } \\
\text { cells and } \\
\text { C57/BL6 } \\
\text { mouse model }\end{array}$ & $\begin{array}{l}\text { The combined EGCG-pNG exerts an } \\
\text { improved effect in inhibiting the } \\
\text { growth of B16F10 melanoma cells } \\
\text { through cell apoptosis. }\end{array}$ & $\begin{array}{l}\text { Chen C. C. et al., } \\
2014\end{array}$ \\
\hline \multicolumn{8}{|c|}{ Mesoporous silica-based EGCG delivery systems } \\
\hline $\begin{array}{l}\text { Colloidal mesoporous } \\
\text { silica (CMS)- EGCG }\end{array}$ & $\begin{array}{l}\text { CMS was dipped } \\
\text { in EGCG solution } \\
\text { for loading EGCG }\end{array}$ & 50 & 66 & - & HeLa cells & $\begin{array}{l}\text { CMS inhibited the collision of EGCG } \\
\text { radicals, prolonged the half-life of } \\
\text { EGCG, and improved the therapeutic } \\
\text { effect of EGCG via inducing cell } \\
\text { apoptosis by increasing } \mathrm{H}_{2} \mathrm{O}_{2} \\
\text { production. }\end{array}$ & Ding et al., 2012 \\
\hline $\begin{array}{l}\text { CMS@PEGA-pVEC } \\
\text { peptide@ EGCG }\end{array}$ & $\begin{array}{l}\text { CMS@peptide } \\
\text { was dipped in } \\
\text { EGCG solution for } \\
\text { loading EGCG }\end{array}$ & 100 & - & $\begin{array}{l}23 \%(\mathrm{pH} 7.4, \\
20 \mathrm{~h}, \text { room } \\
\text { temperature }\end{array}$ & $\begin{array}{l}\text { MCF- } 7 \text { cells } \\
\text { and MCF-7 } \\
\text { tumor-bearing } \\
\text { mice }\end{array}$ & $\begin{array}{l}\text { EGCG induces apoptosis of MCF-7 } \\
\text { cancer cells and reduces the change } \\
\text { of apoptosis-related proteins with no } \\
\text { damage to normal tissue. }\end{array}$ & Ding et al., 2015 \\
\hline \multicolumn{8}{|c|}{ Lipid-based EGCG delivery systems } \\
\hline $\begin{array}{l}\text { EGCG loaded solid } \\
\text { lipid nanoparticles } \\
\text { (EGCG-SLN) }\end{array}$ & $\begin{array}{l}\text { Emulsion-solvent } \\
\text { evaporation } \\
\text { method }\end{array}$ & 157 & 67.2 & $\begin{array}{c}83.9 \%\left(37^{\circ} \mathrm{C}\right. \\
\mathrm{pH} 5,12 \mathrm{~h})\end{array}$ & $\begin{array}{l}\text { MDA-MB } 231 \\
\text { and DU-145 } \\
\text { cells }\end{array}$ & $\begin{array}{l}\text { EGCG-SLN caused an } 8.1 \text {-fold } \\
\text { increase in cytotoxicity of EGCG } \\
\text { against MDA-MB-231 and } 3.8 \text { times } \\
\text { increase against DU-145. }\end{array}$ & $\begin{array}{l}\text { Radhakrishnan } \\
\text { et al., } 2016\end{array}$ \\
\hline EGCG-SLN; & $\begin{array}{l}\text { High shear } \\
\text { homogenization } \\
\text { and ultrasonication } \\
\text { technique }\end{array}$ & $364 \pm 11$ & 83 & $\begin{array}{l}40 \%\left(37^{\circ} \mathrm{C}\right. \\
\mathrm{pH} 1.2,24 \mathrm{~h})\end{array}$ & Caco-2 cells & $\begin{array}{l}\text { Both SLN and NLC were successfully } \\
\text { developed for EGCG protection and } \\
\text { stabilization and can be a useful } \\
\text { platform for the enhancement of } \\
\text { EGCG bioavailability. }\end{array}$ & Frias et al., 2016 \\
\hline $\begin{array}{l}\text { Folic } \\
\text { acid-functionalized } \\
\text { EGCG-loaded NLC }\end{array}$ & $\begin{array}{l}\text { High shear } \\
\text { homogenization } \\
\text { and ultrasonication } \\
\text { technique }\end{array}$ & 300 & 90 & - & Caco-2 cells & $\begin{array}{l}\text { Folic acid functionalization of } \\
\text { EGCG-loaded lipid NPs can } \\
\text { successfully increase its transport } \\
\text { across the intestinal Barrier. }\end{array}$ & Granja et al., 2019 \\
\hline \multicolumn{8}{|c|}{ Chitosan-based EGCG delivery systems } \\
\hline $\begin{array}{l}\text { EGCG-loaded } \\
\text { chitosan-gellan gum } \\
\text { bipolymeric } \\
\text { nanohydrogels }\end{array}$ & $\begin{array}{l}\text { Ionotropic gelation } \\
\text { and polyelectrolyte } \\
\text { complexation } \\
\text { technique }\end{array}$ & 250 & 91.85 & $\begin{array}{l}53.4 \%(\mathrm{pH} \\
7.4,24 \mathrm{~h})\end{array}$ & $\begin{array}{l}\text { P. aeruginosa, } \\
\text { E. coli, B. } \\
\text { subtilis and } S \text {. } \\
\text { aureus }\end{array}$ & $\begin{array}{l}\text { EGCG-loaded nanohydrogels } \\
\text { displayed sustained drug release and } \\
\text { better antibacterial, antioxidant } \\
\text { activity. }\end{array}$ & Dahiya et al., 2017 \\
\hline
\end{tabular}


TABLE 1 | Continued

\begin{tabular}{|c|c|c|c|c|c|c|c|}
\hline $\begin{array}{l}\text { EGCG nano- delivery } \\
\text { system }\end{array}$ & $\begin{array}{l}\text { Synthetic } \\
\text { method }\end{array}$ & $\begin{array}{l}\text { Particle size } \\
\text { (nm) }\end{array}$ & $\begin{array}{c}\text { Encapsulation } \\
\text { efficiency } \\
(\%)\end{array}$ & $\begin{array}{l}\text { Release of } \\
\text { EGCG }\end{array}$ & $\begin{array}{l}\text { Cell } \\
\text { lines/animal } \\
\text { models }\end{array}$ & Achievement & References \\
\hline $\begin{array}{l}\text { Chitosan nanoparticles } \\
\text { encapsulating EGCG } \\
\text { (Chit-nanoEGCG) }\end{array}$ & $\begin{array}{l}\text { Sonication and } \\
\text { dialysis method }\end{array}$ & $150-200$ & in & $\begin{array}{c}10 \% \\
\text { (simulated } \\
\text { gastric juice, } \\
24 \mathrm{~h}) ; 50 \% \\
\text { (simulated } \\
\text { intestinal fluid, } \\
24 \mathrm{~h} \text { ) }\end{array}$ & $\begin{array}{l}\text { 22Rv1 cells } \\
\text { and ahymic } \\
\text { nude mice }\end{array}$ & $\begin{array}{l}\text { Chit-nanoEGCG led to sustained } \\
\text { release of EGCG, inducing poly } \\
\text { (ADP-ribose) polymerases cleavage; } \\
\text { increasing protein expression of Bax } \\
\text { with concomitant decrease in Bcl-2; } \\
\text { activating caspases, reducing Ki-67 } \\
\text { and proliferating cell } 150 \text { nuclear } \\
\text { antigen. }\end{array}$ & Khan et al., 2013 \\
\hline $\begin{array}{l}\text { Folate conjugated } \\
\text { chitosan coated EGCG } \\
\text { nanoparticles } \\
\text { (FCS-EGCG-NPS) }\end{array}$ & $\begin{array}{l}\text { Ionic cross-linking } \\
\text { method }\end{array}$ & 400 & 75 & - & $\begin{array}{l}\text { HeLa, H1299 } \\
\text { and Capan-1 } \\
\text { cells }\end{array}$ & $\begin{array}{l}\text { FCS-EGCG-NPs had a greater tumor } \\
\text { inhibition effect on cancer cells having } \\
\text { a large expression of folic acid } \\
\text { receptors on the surface. }\end{array}$ & Liang et al., 2014 \\
\hline \multicolumn{8}{|c|}{ Protein-based EGCG delivery systems } \\
\hline $\begin{array}{l}\beta \text {-lactoglobulin } \\
(\beta \text {-Lg)-EGCG } \\
\text { nanoparticles }\end{array}$ & $\begin{array}{l}\text { Thermally-induced } \\
\text { protein-EGCG } \\
\text { co-assemblies }\end{array}$ & - & $58.6 \pm 6.8$ & $\begin{array}{c}25 \%\left(37^{\circ} \mathrm{C}\right. \\
180 \mathrm{~min})\end{array}$ & - & $\begin{array}{l}\text { The very limited release from } \\
\beta \text {-Lg-EGCG nanoparticles during } \\
\text { simulated gastric digestion made it a } \\
\text { potential enteric carrier for } \\
\text { polyphenols. }\end{array}$ & $\begin{array}{l}\text { Shpigelman et al., } \\
2012\end{array}$ \\
\hline $\begin{array}{l}\text { EGCG- } \beta \text {-Lg } \\
\text { nanoparticles (E } \beta \text {-NPs) }\end{array}$ & $\begin{array}{l}\text { Thermally-induced } \\
\text { protein-EGCG } \\
\text { co-assemblies }\end{array}$ & $31.3 \pm 0.62$ & 59.2 & - & $\begin{array}{l}\text { FACS. A375 } \\
\text { and TE-1 cells }\end{array}$ & $\begin{array}{l}\text { The E } \beta \text {-NPs possessed better } \\
\text { bioactivity than native EGCG with } \\
\text { respect to the proliferative inhibition of } \\
\text { cancer cells. }\end{array}$ & Wu et al., 2017 \\
\hline $\begin{array}{l}\beta \text {-Lg, } \\
\text { 3-mercapto-1-hexanol } \\
(3 \mathrm{MH}) \text { and EGCG } \\
\text { co-assembled } \\
\text { nanocomplexes } \\
\text { (ME } \beta \text {-NPs) }\end{array}$ & $\begin{array}{l}\text { Thermally-Induced } \\
\text { protein-EGCG } \\
\text { co-assemblies }\end{array}$ & $28.4-32.3$ & $50.2-60.8$ & $\begin{array}{c}62.0 \%\left(37^{\circ} \mathrm{C}\right. \\
24 \mathrm{~h})\end{array}$ & $\begin{array}{l}\text { A375, Hep } \\
\text { G2 and TE-1 } \\
\text { cells }\end{array}$ & $\begin{array}{l}\text { Antioxidant capacity, absorbability } \\
\text { and bioavailability of EGCG in } \\
\text { ME } \beta \text {-NPs was improved, exhibiting } \\
\text { greater stability, sustained release and } \\
\text { anticancer effects in vitro and in vivo } \\
\text { than free EGCG. }\end{array}$ & $\begin{array}{l}\text { Yang Y. et al., } \\
2017\end{array}$ \\
\hline $\begin{array}{l}\text { EGCG-loaded } \\
\beta \text {-lactoglobulin } \\
\text { (BLG)-chlorogenic acid } \\
\text { (CA) conjugates }\end{array}$ & $\begin{array}{l}\text { Free radical } \\
\text { method }\end{array}$ & $105-110$ & $\begin{array}{c}71.8 \% \\
\text { [BLG-CA } \\
\text { (low)]; } 73.5 \% \\
\text { [BLG-CA } \\
\text { (high)] }\end{array}$ & $\begin{array}{c}34.5 \%(\mathrm{pH} \\
7.4,6 \mathrm{~h})\end{array}$ & - & $\begin{array}{l}\text { BLG-CA (high) showed higher } \\
\text { inhibition of EGCG release than } \\
\text { BLG-CA (low), suggesting that CA } \\
\text { exhibited inhibition for digestive } \\
\text { enzymes in intestinal stage. }\end{array}$ & Fan et al., 2017 \\
\hline $\begin{array}{l}\text { Ferritin-chitosan } \\
\text { Maillard reaction } \\
\text { products } \\
\text { (FCMPs)-EGCG } \\
\text { complexes }\end{array}$ & $\begin{array}{l}\text { EGCG solution } \\
\text { was dripped into } \\
\text { FCMPs solution } \\
\text { for EGCG } \\
\text { encapsulating }\end{array}$ & 7.5 & $12.87(w / w)$ & $\begin{array}{l}75.6 \% \\
\text { (simulated } \\
\text { gastric fluid, } \\
160 \mathrm{~min} \text { ) }\end{array}$ & $\begin{array}{l}\text { Caco-2 } \\
\text { monolayer } \\
\text { model }\end{array}$ & $\begin{array}{l}\text { The glycosylated ferritin retained its } \\
\text { shell-like structure and can protect } \\
\text { the encapsulated EGCG in simulated } \\
\text { gastrointestinal tract. The } \\
\text { ferritin-chitosan double shells can } \\
\text { improve the absorption of } \\
\text { encapsulated EGCG in Caco-2 } \\
\text { monolayer model. }\end{array}$ & $\begin{array}{l}\text { Yang R. et al., } \\
2017\end{array}$ \\
\hline
\end{tabular}

of the bioactive chemical cargo. Further, nanovehicles featuring high drug loading, targeted drug transportation, and site-specific drug release significantly improved the bioavailability of EGCG with sufficient concentrations in the lesions, making the precise treatment of cancer possible. To further augment the therapeutic outcomes, the combination of EGCG-dominated chemotherapy with other chemicals ( $\mathrm{Hu}$ et al., 2015; Zhou et al., 2016), therapeutic genes (Ding et al., 2018; Liang et al., 2018), and photothermal agents or photosensitizers (Mun et al., 2014; Qi et al., 2014) has received numerous successes in boosting efficacy and minimizing drawbacks in cancer treatments. This article mainly focuses on recent advances in engineering nanovehicles for EGCG encapsulation and delivery for precise and efficient cancer therapy. Moreover, endeavors devoted to integrating
EGCG-involved chemotherapy with other chemical curative agents, therapeutic genes, and phototherapeutic components in a single nanovehicle for elevating the overall potency are also overviewed.

\section{EGCG DELIVERY SYSTEMS ENABLED BY NANOVEHICLES FOR CANCER THERAPY}

The construction of EGCG-loaded nanovehicles has been generally recognized to enhance the stability and bioavailability of EGCG, exhibiting great potential for practical applications in cancer chemoprevention and chemotherapy. Numerous nanomaterials, including gold nanoparticles, mesoporous silica 
nanostructures, chitosan nanoparticles, lipid nanoparticles, and protein nanoassemblies, can serve as carriers for delivering EGCG to tumor tissues, while the delivery efficiency is highly dependent on the morphological and surface characteristics of nanovehicles (Figure 1). The physiological stability and cellular uptake of nanovehicles in tumor sites relies on the composition, dimension, outer surface chemistry, and electrostatics of the drug-loaded nanoparticles. In addition, targeted delivery and controllable release of the entrapped therapeutic agents is determined by engineering of nanovehicles with recognition ligands and bioresponsive species. In this section, the nanovehicles for EGCG transportation differing in building components, surface functionalities, drug release mechanisms, and biomedical uses are elucidated in detail. The main characteristics of nanostructure-based EGCG delivery systems for cancer treatments are summarized in Table $\mathbf{1 .}$

\section{Gold Nanoparticles-Based EGCG Delivery Systems}

AuNPs-enabled drug delivery systems for cancer chemotherapy have been intensively studied due to their high surface to volume ratio and controllable functionalized surface, which are favorable properties in drug loading and delivery. To date, AuNPs-based EGCG delivery systems have been substantially explored in cancer diagnosis and therapy. Previous research revealed that reduction of $\mathrm{Au}^{3+}$ by EGCG offered a promising synthetic route of $\mathrm{Au}$ nanoparticles with an EGCG-grafted surface (Viator et al., 2010; Shukla et al., 2012; Chavva et al., 2019), which is contributive to improving uptake by tumor cells. Moreover, the radioactive gold source $\left(\mathrm{H}^{198} \mathrm{AuCl}_{4}\right)$ enables a radiotherapeutic effect of EGCG- ${ }^{198}$ AuNPs in killing prostate tumor cells (Shukla et al., 2012). The mixing of EGCG and physical nanogold ( $\mathrm{pNG}$ ) particles is also an effective method for coating EGCG on AuNPs with a prolonged half-life (110 days) (Hsieh et al., 2012). The anti-tumor mechanism of EGCG-pNG is attributed to the mitochondrial pathway-mediated apoptosis, demonstrating a 1.66-fold higher inhibition ratio than free EGCG (Chen C. C. et al., 2014).

\section{Mesoporous Silica-Based EGCG Delivery Systems}

Mesoporous silica nanoparticles (MSNs), with controllable size, ordered porosity, high internal surface area, and easily modified surfaces, have been widely applied for the construction of drug delivery systems. The high corrosion resistance of MSN under physiological conditions provides protection for the encapsulated drugs from degradation before reaching the tumor sites. The high biocompatibility of MSN with negligible cytotoxicity also makes it a safe drug carrier that can be eliminated through renal clearance (Chen et al., 2013; Li et al., 2017). According to a previous study (Ding et al., 2012), MSN can adsorb EGCG through electrostatic attraction and inhibit the collision of EGCG radicals, thus prolonging the half-life of EGCG. Our group further introduced a breast-tumor-homing cell-penetrating peptide onto the EGCG-loaded MSN for the targeted accumulation and release of EGCG in MCF-7 cells (Ding et al., 2015).

\section{Lipid-Based EGCG Delivery Systems}

Nanocapsules with lipids in the matrix could improve their biocompatibility. The high encapsulation efficiency and controlled-release from lipid-based nanovehicles maintain the prolonged efficacy of entrapped drugs. Solid lipid nanoparticles (SLN) consisting of glycerol monostearate, stearic acid, and soya lecithin were used as stealth vehicles for efficient EGCG delivery due to their high biocompatibility, while the erosion or metabolization of lipids led to the sustained release of EGCG (Radhakrishnan et al., 2016). In comparison with SLN, nanostructured lipid carriers (NLC) that consisted of both solid (Precirol ${ }^{\circledR}$ ATO) and liquid (miglyol-812) lipids showed higher encapsulation efficiency (90\%) and stability during long-term storage (Frias et al., 2016). Moreover, more than 60\% of encapsulated EGCG remains in the nanovehicles after contact with simulated gastric and intestinal fluids for $4 \mathrm{~h}$, indicating the feasibility of EGCG-NLC for oral administration. On this basis, folic acid is introduced to make it easier for NLC-based nanovehicles to transport across the intestinal barrier (Granja et al., 2019).

\section{Chitosan-Based EGCG Delivery Systems}

As mentioned above, chitosan can serve as a surface modification agent to increase cellular uptake and conduct on-demand drug release, due to its biocompatibility and biodegradability. In addition, cross-linking agents or other structural promoters were combined in these dose forms to prevent chitosan capsules from burst breaking in acidic medium and ensure its applicability as drug carriers in oral administration. Gellan gum with high resistance to heat and acidic media was employed to construct chitosan-gellan gum bipolymeric nanohydrogels for oral EGCG delivery (Dahiya et al., 2017). The interaction between $-\mathrm{NH}_{2}$ in chitosan and phosphate in pentasodium tripolyphosphate hexahydrate can also enhance the stability of EGCG-entrapped chitosan nanoparticles (Khan et al., 2013). Moreover, folic acid is introduced via the ionic gelation method for targeted EGCG delivery toward cancer cells with overexpressed folic acid receptors (Liang et al., 2014).

\section{Protein-Based EGCG Delivery Systems}

Proteins are effective nanocarriers for drug delivery systems since these renewable biomacromolecules exhibit a high drugbinding capacity with low cytotoxicity, which can also target tumor cells effectively due to the specific recognition of the receptors on tumor cell membranes. Moreover, proteins with a unique structure provide specific binding sites for EGCG, thus further enhancing the stability of encapsulated EGCG in comparison with other nanovehicles (Yang R. et al., 2017). Thermally-induced protein-EGCG co-assembly is a widely used strategy for constructing $\beta$-lactoglobulin $(\beta$-Lg)-based EGCG delivery systems with encapsulation efficiencies between 50 and 60\% (Shpigelman et al., 2012; Wu et al., 2017; Yang Y. et al., 2017). The limited release (25\%) of EGCG in acidic medium (pH $2,37^{\circ} \mathrm{C}, 3 \mathrm{~h}$ ) demonstrates the protection of $\beta$-Lg nanocapsules 
for EGCG from gastric digestion and oxidative degradation (Shpigelman et al., 2012). Moreover, the intestinal absorption of $\beta$-Lg-EGCG nanoparticles ( $<50 \mathrm{~nm}$ ), followed by the sustained release of EGCG in neutral physiological conditions, ensures the high bioavailability of EGCG for cancer therapy. Conjugation of $\beta$-Lg with chlorogenic acid (CA) is another route to isolate the protein-based nanovehicles from enzymatic digestion, resulting in the limited premature release of EGCG during the delivery process (Fan et al., 2017).

In comparison with inorganic nanovehicles (Au NPs and MSN, etc.), organic nanocarriers based on nanolipids, chitosan, and proteins possess a higher encapsulation efficiency and exhibit the controllable release of EGCG. The superior biocompatibility with an easier-to-functionalize surface also makes it possible for targeted delivery and enhanced intercellular accumulation of EGCG. However, the relatively low stability restricts their application for EGCG delivery through oral administration where burst breaking or biodegradation can occur in digestive fluids, resulting in the pre-release and structural change of entrapped EGCG. Therefore, recent research is mainly focused on exploring biomolecule-based nanoplatforms with welldefined nanostructures and sufficient stability for EGCG delivery.

\section{COMBINATION THERAPY BY EGCG-LOADED NANOVEHICLES}

Although a range of EGCG-nanovehicles have contributed to the success in maintaining chemical structure integrity and increasing delivery efficiency, nanovehicle-enabled EGCG delivery for single-drug therapy is still suboptimal due to its inherent defects in pharmacological activities. To upgrade the curative effects of EGCG-involved therapy, it is of great importance to integrate multiple therapeutic approaches actuated by diverse rationales. On the other hand, considering side effects or drug resistance in the medication by conventional chemotherapeutics, gene therapeutics, and photosensitizers, introducing EGCG in the formulation would offer the possibility of boosting the therapeutic efficacy. Nanostructured drug carriers offer a versatile scaffold for the integration of EGCG with other therapeutic agents featuring chemotherapy, gene therapy, and phototherapy in a collaborative manner, rendering combination treatment more effective in curing various cancers. Here, we reviewed the recent progresses made in cancer combination therapy that encompass EGCG and therapeutic agents with different functions, and highlighted the advantages of EGCGinvolved co-delivery nanovehicles.

\section{Combination With Other Chemical Drugs}

Multidrug resistance (MDR) is one of the major problems facing cancer chemotherapy due to the expression of energy-dependent drug efflux pumps on the plasma membrane. Moreover, side effects induced by anticancer drugs are another formidable factor that cause damage to normal tissues during cancer treatment. As is already known, EGCG is a promising candidate that can overcome the drawbacks of conventional chemotherapeutic agents and enhance their anticancer capabilities. The integration of EGCG and DOX is currently the most in-depth studied EGCGinvolved binary therapeutic system. As reported by Yao et al. (2017), DOX-induced cardiotoxicity can be suppressed by EGCG via upregulating the expression of mitochondrial membrane potential and manganese superoxide dismutase. Moreover, EGCG can also ameliorate DOX-evoked oxidative stress injury and activate the ErbB2-involved pro-survival pathway (Saeed et al., 2015). Remarkably, the efficient interaction between EGCG and DOX leads to the high encapsulation efficiency of DOX (88\%) within PEG-EGCG micellar nanocomplexes, improving blood circulation stability and tumor targeting ability of DOX while minimizing its dose-dependent side effects (Liang et al., 2018). In the orchestration of EGCG and DOX, EGCG was reported to inhibit the activity of MMP-2 and MMP-9 that are increased in MCF7/DOX cells, thus sensitizing them to DOX and reducing their metastatic potential (Stearns et al., 2010; Nowakowska and Tarasiuk, 2016). Moreover, the pro-survival autophagy of tumor cells can also be reduced by EGCG through targeting and decreasing autophagy signaling induced by DOX treatment, therefore improving the efficacy of DOX (Chen L. et al., 2014; Wang W. et al., 2018).

\section{Combination With Gene Therapy}

Gene therapy is achieved by counteracting or replacing a malfunctioning gene within the cells, and exhibits great potential to treat various cancers at their genetic roots (Naldini, 2015). In particular, the sequence-specific gene silencing induced by RNA interference (RNAi) can modulate the immune response, regulate the cell cycle, inhibit the overexpressed oncogenes, induce apoptosis of tumor cells, and has anti-angiogenesis effect, which can also amplify the efficacy of chemotherapeutic agents. Recently, the enhanced therapeutic efficacy derived from the integration of EGCG and therapeutic genes has caught great attention. It has been confirmed that 28 genes related to the pro-apoptotic (activate) and pro-survival (inhibit) of Hs578T cells are altered by the combination treatment of EGCG and p53siRNA (Braicu et al., 2015). The integration of specific siRNA and EGCG can also reverse the drug resistance of tumor cells to conventional chemotherapy agents such as tamoxifen (Esmaeili, 2015). Based on investigations at the cellular level, nanovehicles were developed for co-delivering therapeutic genes and EGCG to realize the combined treatment of cancer in vivo. As reported by Ding et al. (2018), siRNA and EGCG are self-assembled to form a stealth nanovehicle using protamine as the assembly skeleton, which can accommodate the two therapeutic agents and minimize side effects. In addition, the as-obtained nanovehicles modified with hyaluronic acid and tumor-homing cell-penetrating peptide demonstrated superior selectivity toward drug-resistant MDA-MB-231 cell lines with marked enhancement in cytotoxicity, which is 15 times greater than free EGCG.

\section{Combination With Phototherapy}

Photodynamic therapy (PDT) is an emerging cancer treatment strategy based on the photochemical reactions aroused by photosensitizers, which can produce ROS with high cytotoxicity under irradiation at specific wavelengths, thereby inducing 
apoptosis of tumor cells and causing damage to tumor tissues. The superposition of EGCG-dominated chemotherapy and PDT in a single nanostructured entity provides a practical approach to enhance cancer therapeutic efficacy. The synergism of PDT (Radachlorin, $662 \mathrm{~nm}$ laser) and EGCG via intratumoral injection leads to the increased expression of primary antibodies, such as p21, p53, Bax, and PARP, causing significant enhancement in TC-1 tumor cell growth inhibition compared to PDT or EGCG-involved therapy alone (Mun et al., 2014). In addition, the irradiation of pulsed laser light can in turn contribute to transmembrane convection of EGCG by modulating the nanostructure of water layers in tumor cells (Sommer et al., 2011). In view of the synergism between EGCG and PDT, the photoreponsive nanovehicles are in great demand for EGCG delivery and release. However, related research is still rare. Notably, DOXloaded EGCG-Fe(III) networks have been demonstrated to realize chemo- and photothermal therapy (PTT) simultaneously (Chen et al., 2019). Specifically, the photothermal capability of EGCG-Fe(III) networks under near-infrared irradiation cause damage to HT-29 cells through hyperthermia, thus reinforcing the chemotherapy efficacy of DOX in inducing tumor cell apoptosis and eventually ablating the solid tumor completely. Anisotropic gold nanostructures with fascinating photothermal properties can act as nanocarriers for delivering therapeutic molecules, but their uses in EGCG loading for chemo-photothermal combination therapy are still seldom reported. The recruitment of anisotropic gold nanostructures is a promising complement to EGCG for improving cancer therapy efficacy.

\section{CONCLUSIONS}

This review summarizes the achievements of various popular nanovehicles for EGCG delivery in vitro and in vivo. The recent progresses showed that nanovehicles designed with structural characteristics and surface functionalities allowed targeted delivery and controllable release of EGCG with enhanced stability and bioavailability. However, clinical applications of these EGCG-containing nanoplatforms are still limited. The chemically stable AuNPs and MSNs suffered severe accumulation in the liver and spleen, potentially causing toxicity to the human body. Meanwhile, the biodegradation

\section{REFERENCES}

Berletch, J. B., Liu, C., Love, W. K., Andrews, L. G., Katiyar, S. K., and Tollefsbol, T. O. (2008). Epigenetic and genetic mechanisms contribute to telomerase inhibition by EGCG. J. Cell. Biochem. 103, 509-519. doi: 10.1002/jcb.21417

Braicu, C., Pileczki, V., Pop, L., Petric, R. C., Chira, S., and Pointiere, E. (2015). Dual targeted therapy with p53 siRNA and epigallocatechingallate in a triple negative breast cancer cell model. PLoS ONE 10:e120936. doi: 10.1371/journal.pone.0120936

Cai, Y. Z., Mei, S., Jie, X., Luo, Q., and Corke, H. (2006). Structureradical scavenging activity relationships of phenolic compounds from traditional ChinesChakrabartie medicinal plants. Life Sci. 78, 2872-2888. doi: 10.1016/j.lfs.2005.11.004 of organic nanoparticles (e.g., nanolipid-based, chitosan-based, and protein-based nanoparticles) in digestive fluids may restrict their application for EGCG delivery through oral administration. Therefore, it is essential and urgent to develop nanocarriers with considerable stability, biocompatibility, efficiency, and safety, which would be adaptive to clinical practices of EGCG-involved therapy in the future. To this end, more attention should be paid to non-toxic and biodegradable nanomaterials with high internal surface areas, such as layered double hydroxides (LDHs), blank phosphorus (BP), and metal organic frameworks (MOFs), although studies on them for EGCG delivery are still lacking.

In comparison with the single-drug delivery systems, integration of EGCG with other therapeutic agents enabling chemotherapy, gene therapy, or phototherapy to form multifunctional nanoplatforms appears to be an ideal strategy in enhancing the efficacy of cancer treatment. Moreover, fully understanding the working principles of EGCG and other chemo-, gene, and phototherapeutic agents in cancer cells offer theoretical evidence supporting combination therapy, according to which arrangement and gathering of therapeutic agents in one nanostructure can be rationalized to maximize the potency and minimize the undesired effects. Guided by the mechanisms of synergistic action in combination therapy, we can envision that interfaces between EGCG chemotherapy and other emerging therapeutic modalities including starvation therapy, gas therapy, chemodynamic therapy, and immunity therapy would be further explored and engineered to formulate comprehensive and effective combination treatments of cancer.

\section{AUTHOR CONTRIBUTIONS}

KL designed and wrote the review with input from CT and QM for conceiving, writing, and editing the manuscript. All authors contributed to the article and approved the submitted version.

\section{FUNDING}

This study was supported by Shenzhen Science and Technology Innovation Committee (GJHZ20190819151807167), Postdoctoral Foundation Project of Shenzhen Polytechnic, and the Fundamental Research Funds for the Central Universities (020514380141), and Chinese Postdoctoral Science Foundation (2020M671437). 
Chen, L., Ye, H. L., Zhang, G., Yao, W. M., Chen, X. Z., Zhang, F. C., et al. (2014). Autophagy inhibition contributes to the synergistic interaction between EGCG and Doxorubicin to kill the hepatoma Hep3B cells. PLoS ONE 9:e85771. doi: 10.1371/journal.pone.0085771

Chen, X., Yi, Z., Chen, G., Ma, X., Su, W., Cui, X., et al. (2019). DOXassisted functionalization of green tea polyphenol nanoparticles for effective chemo-photothermal cancer therapy. J. Mater. Chem. B 7, 4066-4078. doi: 10.1039/C9TB00751B

Chen, Y., Chen, H., and Shi, J. (2013). In vivo bio-safety evaluations and diagnostic/therapeutic applications of chemically designed mesoporous silica nanoparticles. Adv. Mater. 25, 3144-3176. doi: 10.1002/adma.201205292

Cragg, G. M., Grothaus, P. G., and Newman, D. J. (2009). Impact of natural products on developing new anti-cancer agents. Chem. Rev. 109, 3012-3043. doi: $10.1021 / \mathrm{cr} 900019 \mathrm{j}$

Dahiya, S., Rani, R., Kumar, S., Dhingra, D., and Dilbaghi, N. (2017). Chitosan-gellan gum bipolymeric nanohydrogels-a potential nanocarrier for the delivery of epigallocatechin gallate. BioNanoSci 7, 508-520. doi: 10.1007/s12668-017-0416-0

Ding, J., Kong, X., Yao, J., Wang, J., Cheng, X., Tang, B., et al. (2012). Core-shell mesoporous silica nanoparticles improve HeLa cell growth and proliferation inhibition by (-)-epigallocatechin-3-gallate by prolonging the half-life. J. Mater. Chem. 22, 19926-19931. doi: 10.1039/c2jm32271d

Ding, J., Liang, T., Min, Q., Jiang, L., and Zhu, J. J. (2018). "Stealth and fully-laden" drug carriers: Self-assembled nanogels encapsulated with epigallocatechin gallate and siRNA for drug-resistant breast cancer therapy. ACS Appl. Mater. Interfaces 10, 9938-9948. doi: 10.1021/acsami.7b19577

Ding, J., Yao, J., Xue, J., Li, R., Bao, B., Jiang, L., et al. (2015). Tumor-homing cell-penetrating peptide linked to colloidal mesoporous silica encapsulated ()-epigallocatechin-3-gallate as drug delivery system for breast cancer therapy in vivo. ACS Appl. Mater. Interfaces 7, 18145-18155. doi: 10.1021/acsami.5b 05618

Esmaeili, M. A. (2015). Combination of siRNA-directed gene silencing with epigallocatechin-3-gallate (EGCG) reverses drug resistance in human breast cancer cells. J. Chem. Biol. 9, 41-52. doi: 10.1007/s12154-015-0144-2

Fan, Y., Zhang, Y., Yokoyama, W., and Yi, J. (2017). $\beta$-Lactoglobulin-chlorogenic acid conjugate-based nanoparticles for delivery of (-)-epigallocatechin-3gallate. RSC Adv. 7, 21366-21374. doi: 10.1039/C6RA28462K

Frias, I., Neves, A., Pinheiro, M., and Reis, S. (2016). Design, development, and characterization of lipid nanocarriers-based epigallocatechin gallate delivery system for preventive and therapeutic supplementation. Drug Des. Dev. Ther. 10, 3519-3528. doi: 10.2147/DDDT.S109589

Gan, R. Y., Li, H. B., Sui, Z. Q., and Corke, H. (2017). Absorption, metabolism, anti-cancer effect and molecular targets of epigallocatechin gallate (EGCG): an updated review. Crit. Rev. Food Sci. Nutr. 58, 924-941. doi: 10.1080/10408398.2016.1231168

Granja, A., Neves, A. R., Sousa, C. T., Pinheiro, M., and Reis, S. (2019). EGCG intestinal absorption and oral bioavailability enhancement using folic acid-functionalized nanostructured lipid carriers. Heliyon 5:e02020. doi: 10.1016/j.heliyon.2019.e02020

Granja, A., Pinheiro, M., and Reis, S. (2016). Epigallocatechin gallate nanodelivery systems for cancer therapy. Nutrients 8:307. doi: 10.3390/nu8050307

Hsieh, D. S., Lu, H. C., Chen, C. C., Wu, C. J., and Yeh, M. K. (2012). The preparation and characterization of gold-conjugated polyphenol nanoparticles as a novel delivery system. Int. J. Nanomed. 7, 1623-1633. doi: 10.2147/IJN.S30060

Hu, F., Wei, F., Wang, Y., Wu, B., Fang, Y., and Xiong, B. (2015). EGCG synergizes the therapeutic effect of cisplatin and oxaliplatin through autophagic pathway in human colorectal cancer cells. J. Pharmacol. Sci. 128, 27-34. doi: 10.1016/j.jphs.2015.04.003

Khan, N., Bharali, D. J., Adhami, V. M., Siddiqui, I. A., Cui, H., Shabana, S. M., et al. (2013). Oral administration of naturally occurring chitosanbased nanoformulated green tea polyphenol EGCG effectively inhibits prostate cancer cell growth in a xenograft model. Carcinogenesis 35, 415-423. doi: $10.1093 /$ carcin/bgt321

Li, G. X., Chen, Y. K., Hou, Z., Xiao, H., Jin, H., Lu, G., et al. (2010). Pro-oxidative activities and dose-response relationship of (-)-epigallocatechin-3-gallate in the inhibition of lung cancer cell growth: a comparative study in vivo and in vitro. Carcinogenesis 31, 902-910. doi: 10.1093/carcin/bgq039
Li, Y., Li, N., Pan, W., Yu, Z., Yang, L., and Tang, B. (2017). Hollow mesoporous silica nanoparticles with tunable structures for controlled drug delivery. ACS Appl. Mater. Interfaces 9, 2123-2129. doi: 10.1021/acsami.6b13876

Liang, J., Cao, L., Zhang, L., and Wan, X. C. (2014). Preparation, characterization, and in vitro antitumor activity of folate conjugated chitosan coated EGCG nanoparticles. Food Sci. Biotechnol. 23, 569-575. doi: 10.1007/s10068-014-0078-4

Liang, T., Yao, Z., Ding, J., Min, Q., Jiang, L. P., and Zhu, J. J. (2018). Cascaded aptamers-governed multistage drug delivery system based on biodegradable envelope type nanovehicle for targeted therapy of HER2-overexpressing breast cancer. ACS Appl. Mater. Interfaces. 10, 34050-9. doi: 10.1021/acsami.8b14009

Mignani, S., Rodrigues, J., Tomas, H., Zablocka, M., Shi, X., Caminade, A. M., et al. (2018). Dendrimers in combination with natural products and analogues as anti-cancer agents. Chem. Soc. Rev. 47, 514-532. doi: 10.1039/C7CS00550D

Mun, S. T., Bae, D. H., and Ahn, W. S. (2014). Epigallocatechin gallate with photodynamic therapy enhances anti-tumor effects in vivo and in vitro. Photodiagn. Photodyn. Ther. 11, 141-147. doi: 10.1016/j.pdpdt.2014.03.003

Nakagawa, K., and Miyazawa, T. (1997). Chemiluminescence-high-performance liquid chromatographic determination of tea catechin, (-)-epigallocatechin 3gallate, at picomole levels in rat and human plasma. Anal. Biochem. 248, 41-49. doi: 10.1006/abio.1997.2098

Naldini, L. (2015). Gene therapy returns to centre stage. Nature 526, 351-360. doi: $10.1038 /$ nature 15818

Nowakowska, A., and Tarasiuk, J. (2016). Comparative effects of selected plant polyphenols, gallic acid and epigallocatechin gallate, on matrix metalloproteinases activity in multidrug resistant MCF7/DOX breast cancer cells. Acta Biochim. Pol. 63, 571-575. doi: 10.18388/abp.2016_1256

Qi, H., Abe, N., Zhu, B., Murata, Y., and Nakamura, Y. (2014). ()-Epigallocatechin-3-gallate ameliorates photodynamic therapy responses in an in vitro $\mathrm{T}$ lymphocyte model. Phytother. Res. 28, 1486-1491. doi: $10.1002 /$ ptr.5152

Radhakrishnan, R., Kulhari, H., Pooja, D., Gudem, S., Bhargava, S., Shukla, R., et al. (2016). Encapsulation of biophenolic phytochemical EGCG within lipid nanoparticles enhances its stability and cytotoxicity against cancer. Chem. Phys. Lipids 198, 51-60. doi: 10.1016/j.chemphyslip.2016.05.006

Sadava, D., Whitlock, E., and Kane, S. E. (2007). The green tea polyphenol, epigallocatechin-3-gallate inhibits telomerase and induces apoptosis in drugresistant lung cancer cells. Biochem. Biophys. Res. Commun. 360, 233-237. doi: 10.1016/j.bbrc.2007.06.030

Saeed, N. M., El-Naga, R. N., El-Bakly, W. M., Abdel-Rahman, H. M., and El-Demerdash, E. (2015). Epigallocatechin-3-gallate pretreatment attenuates doxorubicin-induced cardiotoxicity in rats: a mechanistic study. Biochem. Pharmacol. 95, 145-155. doi: 10.1016/j.bcp.2015.02.006

Shankar, S., Marsh, L., and Srivastava, R. K. (2012). EGCG inhibits growth of human pancreatic tumors orthotopically implanted in Balb $\mathrm{C}$ nude mice through modulation of FKHRL1/FOXO3a and neuropilin. Mol. Cell. Biochem. 372, 83-94. doi: 10.1007/s11010-012-1448-y

Shpigelman, A., Cohen, Y., and Livney, Y. D. (2012). Thermally-induced $\beta$ lactoglobuline-EGCG nanovehicles: loading, stability, sensory and digestiverelease study. Food Hydrocolloids 29, 57-67. doi: 10.1016/j.foodhyd.2012.01.016

Shukla, R., Chanda, N., Zambre, A., Upendran, A., Katti, K., Kulkarni, R. R., et al. (2012). Laminin receptor specific therapeutic gold nanoparticles ( ${ }^{198} \mathrm{AuNP}-$ EGCg) show efficacy in treating prostate cancer. Proc. Natl. Acad. Sci. U.S.A. 109, 12426-12431. doi: 10.1073/pnas.1121174109

Singh, B. N., Shankar, S., and Srivastava, R. K. (2011). Green tea catechin, epigallocatechin-3-gallate (EGCG): Mechanisms, perspectives and clinical applications. Biochem. Pharmacol. 82, 1807-1821. doi: 10.1016/j.bcp.2011.07.093

Singh, T., and Katiyar, S. K. (2013). Green tea polyphenol, (-)-epigallocatechin3-gallate, induces toxicity in human skin cancer cells by targeting beta-catenin signaling. Toxicol. Appl. Pharmacol. 273, 418-424. doi: 10.1016/j.taap.2013.09.021

Sommer, A. P., Zhu, D., Mester, A. R., and Försterling, H. D. (2011). Pulsed laser light forces cancer cells to absorb anticancer drugs-The role of water in nanomedicine. Artif. Cells Blood Substit. Biotechnol. 39, 169-173. doi: 10.3109/10731199.2010.516262

Spradlin, J. N., Hu, X., Ward, C. C., Brittain, S. M., Jones, M. D., Ou, L., et al. (2019). Harnessing the anti-cancer natural product nimbolide for targeted 
protein degradation. Nat. Chem. Biol. 15, 747-755. doi: 10.1038/s41589-0190304-8

Stearns, M. E., Amatangelo, M. D., Varma, D., Sell, C., and Goodyear, S. M. (2010). Combination therapy with epigallocatechin-3-gallate and Doxorubicin in human prostate tumor modeling studies. Am. J. Pathol. 177, 3169-3179. doi: 10.2353/ajpath.2010.100330

Viator, J. A., Gupta, S., Goldschmidt, B. S., Bhattacharyya, K., Kannan, R., Shukla, R., et al. (2010). Gold nanoparticle mediated detection of prostate cancer cells using photoacoustic flowmetry with optical reflectance. J. Biomed. Nanotechnol. 6, 187-191. doi: 10.1166/jbn.2010.1105

Wang, J., Man, G. C. W., Chan, T. H., Kwong, J., and Wang, C. C. (2018). A prodrug of green tea polyphenol (-)-epigallocatechin-3-gallate (Pro-EGCG) serves as a novel angiogenesis inhibitor in endometrial cancer. Cancer Lett. 412, 10-20. doi: 10.1016/j.canlet.2017.09.054

Wang, W., Chen, D., and Zhu, K. (2018). SOX2OT variant 7 contributes to the synergistic interaction between EGCG and Doxorubicin to kill osteosarcoma via autophagy and stemness inhibition. J. Exp. Clin. Cancer Res. 37:37. doi: 10.1186/s13046-018-0689-3

Wu, M., Jin, J., Jin, P., Xu, Y., Yin, J., Qin, D., et al. (2017). Epigallocatechin gallate- $\beta$-lactoglobulin nanoparticles improve the antitumor activity of EGCG for inducing cancer cell apoptosis. J. Funct. Foods 39, 257-263. doi: 10.1016/j.jff.2017.10.038

Xia, P., and Xu, X. Y. (2015). PI3K/Akt/mTOR signaling pathway in cancer stem cells: From basic research to clinical application. Am. J. Cancer Res. 5, 1602-1609.

Yang, Q. Q., Wei, X. L., Fang, Y. P., Gan, R. Y., Wang, M., Ge, Y. Y., et al. (2019). Nanochemoprevention with therapeutic benefits: an updated review focused on epigallocatechin gallate delivery. Crit. Rev. Food Sci. Nutr. 60, 1243-1264. doi: 10.1080/10408398.2019.1565490

Yang, R., Liu, Y., Gao, Y., Wang, Y., Blanchard, C., and Zhou, Z. (2017). Ferritin glycosylated by chitosan as a novel EGCG nano-carrier: structure, stability, and absorption analysis. Int. J. Biol. Macromol. 105, 252-261. doi: 10.1016/j.ijbiomac.2017.07.040

Yang, Y., Jin, P., Zhang, X., Ravichandran, N., Ying, H., Yu, C., et al. (2017). New epigallocatechin gallate (EGCG) nanocomplexes co-assembled with 3-mercapto-1-hexanol and $\beta$-lactoglobulin for improvement of antitumor activity. J. Biomed. Nanotechnol. 13, 805-814. doi: 10.1166/jbn.2017.2400

Yao, Y. F., Liu, X., Li, W. J., Shi, Z. W., Yan, Y. X., Wang, L. F., et al. (2017). (-)-Epigallocatechin-3-gallate alleviates doxorubicin-induced cardiotoxicity in sarcoma 180 tumor-bearing mice. Life Sci. 180, 151-159. doi: 10.1016/j.lfs.2016.12.004

Ye, J. H., and Augustin, M. A. (2018). Nano- and micro-particles for delivery of catechins: Physical and biological performance. Crit. Rev. Food Sci. Nutr. 59, 1563-1579. doi: 10.1080/10408398.2017.1422110

Zhou, Y., Tang, J., Du, Y., Ding, J., and Liu, J. Y. (2016). The green tea polyphenol EGCG potentiates the antiproliferative activity of sunitinib in human cancer cells. Tumor Biol. 37, 8555-8566. doi: 10.1007/s13277-015-4719-x

Zhu, J., Jiang, Y., Yang, X., Wang, S., Xie, C., Li, X., et al. (2017). Wnt/Bcatenin pathway mediates (-)-Epigallocatechin-3-gallate (EGCG) inhibition of lung cancer stem cells. Biochem. Biophys. Res. Commun. 482, 15-21. doi: 10.1016/j.bbrc.2016.11.038

Conflict of Interest: The authors declare that the research was conducted in the absence of any commercial or financial relationships that could be construed as a potential conflict of interest.

Copyright (c) $2020 \mathrm{Li}$, Teng and Min. This is an open-access article distributed under the terms of the Creative Commons Attribution License (CC BY). The use, distribution or reproduction in other forums is permitted, provided the original author(s) and the copyright owner(s) are credited and that the original publication in this journal is cited, in accordance with accepted academic practice. No use, distribution or reproduction is permitted which does not comply with these terms. 